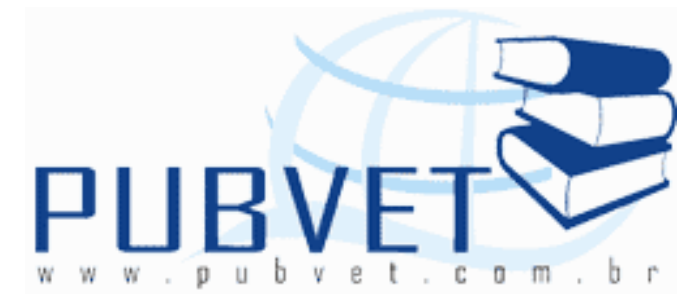

PUBVET, Publicações em Medicina Veterinária e Zootecnia.

\title{
Utilização da silagem para alimentação de equinos
}

\section{Camila Raineri ${ }^{1}$, Thayla Sara Soares Stivari $^{1}$}

${ }^{1}$ Pós Graduação em Nutrição e Produção Animal da Faculdade de Medicina Veterinária e Zootecnia. Departamento de Nutrição e Produção Animal. Universidade de São Paulo.

\section{Resumo}

Na maioria das criações zootécnicas, os gastos com alimentação representam cerca de $60 \%$ dos custos. No caso da equinocultura esse valor pode ser ainda mais elevado, pois os animais são muito sensíveis à dieta, exigindo matérias primas de excelente qualidade. Além disso, cavalos e muares são animais de performance e, como qualquer atleta, têm necessidades especiais de nutrição. Em comparação aos ruminantes, eqüinos possuem capacidade digestiva muito reduzida, com menor aproveitamento de alimentos ricos em fibras e proteínas de baixo valor biológico, e pobres em açúcar, amido e gorduras. Desta forma, as matérias primas fornecidas a eqüinos devem ser de alta qualidade e, portanto, mais caras. A silagem é um excelente volumoso, fonte de fibras, energia e proteína, dependendo da forragem de que é produzida. Assim, pode representar uma alternativa para diminuir custos de manutenção de haras e fazendas, especialmente na época da seca quando o feno alcança preços muito elevados. Apesar de ser encarado com desconfiança por muitos criadores e proprietários, este alimento é utilizado com certa freqüência na Europa sem 
RAINERI, C. e STIVARI, S.S. Utilização da silagem para alimentação de eqüinos. PUBVET, Londrina, V. 7, N. 24, Ed. 247, Art. 1636, Dezembro, 2013.

prejuízo nenhum aos animais, desde que produzido com cuidado e fornecido adequadamente.

Palavras-chave: alimento alternativo, cavalo, equinocultura, volumoso.

\title{
Use of silage in horse nutrition
}

\begin{abstract}
In most of animal raisings, feeding expenses represent about $60 \%$ of all costs. In horse breeding, that value may be even higher, because this animal is very sensitive to diet, demanding excellent quality ingredients. Besides, horses are performance animals, and like any other athletes, have special nutritional needs. In comparison to ruminants, horses have reduced digestive capacity, with lower ability to digest foods rich in fiber and protein with low biological value, and poor in carbohydrates, starch and fat. Therefore, ingredients offered to horses must be high quality, consequently, more expensive. Silage is an excellent roughage, a source of fiber, energy and protein, depending on the forage used to produce it. Thus, it can represent an alternative to reduce maintenance costs of studs and farms, especially on the dry season, when hay becomes very expensive. Despite being suspiciously considered by many breeders and owners, this food is quite frequently used in Europe without any hazard to the animals, since carefully produced and adequately offered.
\end{abstract}

Keywords: alternative feed, forage, roughage.

\section{Introdução}

\subsection{Silagem e Ensilagem}

De acordo com RUIZ, (1992) ensilagem é o processo de alterações físicoquímicas e organolépticas de uma forrageira ou alimento úmido na ausência de ar. Seu principal objetivo é obter uma produção suficiente de ácido lático de origem microbiana para conservação do volumoso; e silagem é um alimento 
RAINERI, C. e STIVARI, S.S. Utilização da silagem para alimentação de eqüinos. PUBVET, Londrina, V. 7, N. 24, Ed. 247, Art. 1636, Dezembro, 2013.

úmido e suculento, resultante da fermentação controlada de uma forrageira fresca armazenada em um silo, sob condições de anaerobiose.

A produção de matéria verde durante a época das águas representa $85 \%$ de todo o volume produzido ao longo do ano. Por essa razão, o excedente da produção é armazenado na forma de silagem, que é utilizada como alimento para os animais, especialmente ruminantes, no período do inverno - quando a produtividade dos pastos é muito reduzida (ANDRIGUETTO et al., 1983).

\subsection{Transformações Durante o Processo de Ensilagem}

O processo de ensilagem, que dura no mínimo 21 dias, pode ser dividido em três etapas. Na primeira ocorre o consumo do $\mathrm{O}_{2}$ residual pelas células das plantas recém-armazenadas, o que contribui para a formação do ambiente anaeróbico. Na segunda, as bactérias do grupo coliforme produzem ácido acético, fazendo $\mathrm{o} \mathrm{pH}$ cair de aproximadamente 7,0 para 6,5 . Na última fase de fermentação os lactobacilos e estreptococos se multiplicam, liberando ácido lático que muda o pH para 4,0 a 4,5. O pH ideal da silagem, atingido em cerca de um mês, situa-se entre 3,5 e 4,2, no qual nenhum desses microrganismos sobreviverá. Ou seja, pode-se dizer que ocorre um feedback negativo entre o $\mathrm{pH}$ e o desenvolvimento das bactérias, pois à medida que aquele cai estas têm seu crescimento limitado até desaparecerem (RUIZ,1992).

\subsection{Cuidados para se obter uma boa Silagem}

Segundo JOBIM (2001), para se obter uma silagem de boa qualidade devem ser observados três pontos: aspectos físicos, disponibilidade de substratos nutritivos e presença de microrganismos desejáveis. $O$ ambiente ideal para o desenvolvimento do processo é de umidade ótima para a planta e ausência de ar. O milho com 35\% de matéria seca é suficiente. Forrageiras em geral precisam sofrer pré-murchamento para atingirem esse valor. Abaixo de $70 \%$ de umidade o Clostridium botulinum, causador do botulismo, não se desenvolve. Caso contrário, essa bactéria tem sua tolerância aos ácidos lático 
RAINERI, C. e STIVARI, S.S. Utilização da silagem para alimentação de eqüinos. PUBVET, Londrina, V. 7, N. 24, Ed. 247, Art. 1636, Dezembro, 2013.

e acético aumentada, e a silagem torna-se fonte de infecção para os animais que a consumirem.

É importante ressaltar que os eqüinos são particularmente suceptíveis a essa doença, principalmente em se tratando dos tipos C e D. UZAL et al. (1997) reportaram a morte de oito cavalos devido à alimentação com volumoso contaminado por suas toxinas. Quantidades de toxinas botulínicas que são subletais nos ratos, rapidamente provocam a morte de cavalos adultos quando administrados por via endovenosa. Por isso, a imunização do gado contra o $C$. botulinum é realizada mediante aplicação de plasma eqüino contendo anticorpos contra o tipo B. O microrganismo aparece também como habitante normal do trato intestinal de cavalos, gado e aves, multiplicando-se e sendo disseminado no ambiente. Carcaças de pequenos animais também são vias de contaminação dos alimentos por Clostridium spp. (RUIZ, 1992).

Os substratos para os microrganismos que realizam essas transformações são carboidratos solúveis, como o amido. Quanto maiores os níveis dessa substância na planta, melhor é a forragem para ensilar. Por essa razão, o milho é a forrageira mais utilizada para esse fim. Também podem ser utilizadas outras gramíneas, como o capim-elefante (Pennisetum sp.), Tanzânia, Pensacola, entre outros. As leguminosas, como a alfafa e a soja, não são muito utilizadas pois seu alto teor protéico age como tamponante, dificultando a queda do $\mathrm{pH}$ e resultando em uma silagem de qualidade inferior (ANDRIGUETTO et al., 1983).

Além do Clostridium botulinum, outros microrganismos indesejáveis podem aparecer caso a ensilagem não seja bem realizada. Baixos teores de umidade dificultam a compactação e criação de um ambiente anaeróbico, facilitando o surgimento de fungos. A ausência de pré-murchamento de gramíneas e a má vedação também favorecem o desenvolvimento de Listeria monocitogenes (RUIZ, 1992). Essa bactéria, presente no solo, é associada principalmente a problemas nervosos nos cavalos (MEYER,1995).

Micotoxinas como aflatoxinas, substância tóxica produzida por fungos Aspergillus spp., podem contaminar milho, soja, sementes de algodão ou 
amendoim. O consumo de alimentos contaminados pode resultar em sérios danos hepáticos e renais (NRC, 1989).

Após um mês do fechamento do silo as reações de fermentação já ocorreram e ele já se encontra pronto para o consumo, mas geralmente levase de 4 a 5 meses para abri-lo. Esse é o período em que os pastos tornam-se escassos e o uso do material ensilado se faz necessário. Uma vez aberto o silo, o ambiente anaeróbico se desfaz e as porções do alimento em contato com o ar tornam-se suceptíveis ao desenvolvimento de espécies de Leveduras, que utilizam como substrato o ácido lático (DANIEL et al., 1970). Dependendo da espécie de Levedura que atacar a silagem, pode-se levar mais ou menos tempo para a deterioração (JONSSON \& PAHLOW, 1984).

\subsection{Cuidados ao se Oferecer Silagem a Eqüinos}

Embora a silagem seja mais freqüentemente utilizada para ruminantes, em especial para gado leiteiro, pode-se ofertar esse alimento também para eqüinos. Essa não é uma prática comum, pois o feno é a técnica de conservação de volumoso mais usual no mundo hípico. MEYER (1995), afirma que na ensilagem de capins ocorrem menores perdas nutricionais e de caroteno que na fenação.

Também a produção de silagem não é tão exigente em termos de condições meteorológicas quanto a de feno. De qualquer forma, o fornecimento de silagem para cavalos exige vários cuidados.

Animais que não estão acostumados a esse alimento devem ser adaptados gradual e progressivamente, parcelando-se a quantidade total em várias vezes ao dia, mesmo porque os animais podem estranhar seu cheiro e gosto (ANDRIGUETTO et al., 1983).

O tamanho das partículas da silagem também deve ser observado com cuidado, pois pedaços muito grandes e talos podem ferir a boca do animal e, se picada muito pequena (abaixo de $2 \mathrm{~cm}$ ), a silagem de milho pode causar obstrução de íleo (MEYER, 1995). 
A silagem não deve ser utilizada como única fonte de alimentação, pois trata-se de um alimento essencialmente energético, sendo, em sua maioria, pobre em proteína, Ca e P (ANDRIGUETTO et al., 1983).

Devido aos problemas com microrganismos e fermentações posteriores à abertura do silo, causadas por microrganismos indesejáveis como o $C$. botulinum, existem na Europa à venda quantidades médias de silagem embaladas a vácuo. Mesmo assim, já houve casos de botulismo e outras doenças associadas a esse produto (MARCENAC, 1990).

\section{Tipos de Silagem Utilizados para Eqüinos}

\subsection{Silagem de milho}

O amido é digerido, na sua maior parte, no intestino delgado do cavalo pela ação das amilases e maltases, e a glicose liberada é absorvida nas paredes do jejuno e íleo. Até o final do intestino delgado, 60 a 95\% do amido de cereais é digerido, sendo o amido do milho em menor proporção do que o da aveia (MEYER, 1995).

Vários fatores podem influenciar a digestibilidade do amido para eqüinos. Segundo PILLINER (1992), sua estrutura química e o período de tempo em que o material permanece no intestino delgado afetam a digestibilidade deste carboidrato. Por outro lado, fatores individuais como hábito alimentar (mastigação) e a atividade da amilase no intestino delgado podem levar a diferenças consideráveis na digestibilidade do amido de animal para animal.

Em condições normais de alimentação, parte do amido da dieta chega ao intestino grosso, passando intacto à ação das enzimas no intestino delgado. Este amido residual, que escapa da digestão no intestino delgado, é fermentado no ceco (KIENZLE, 1994).

Por essa razão, é preocupante o uso de alimentos amiláceos ou fermentados na nutrição de eqüinos, pois, quando grandes quantidades de amido (erros alimentares/deficiência no processo absortivo) entram no 
RAINERI, C. e STIVARI, S.S. Utilização da silagem para alimentação de eqüinos. PUBVET, Londrina, V. 7, N. 24, Ed. 247, Art. 1636, Dezembro, 2013.

intestino grosso do cavalo, podem ocorrer sérios distúrbios digestivos, induzindo o surgimento de diarréia, cólica ou laminite (WOLTER, 1977).

SANTOS et al. (2002), desenvolveram estudos com objetivo de avaliar a substituição parcial e total do grão de milho seco pela silagem de grãos úmidos de milho, em rações para eqüinos em crescimento, por meio de ensaios de digestibilidade e de desempenho, chegando às seguintes conclusões:

- Os nutrientes digestíveis da silagem de grãos úmidos de milho, avaliado

com eqüinos, são 86,66\% para matéria seca, 4,94\% para proteína, 0,83\% para fibra, 3,56\% para fibra em detergente neutro, 1,28\% para fibra em detergente ácido, 70,63\% para o amido e $3.667 \mathrm{kcal} / \mathrm{kg}$ para a energia, com base na matéria seca.

- Os valores obtidos para os coeficientes de digestibilidade para a silagem de grãos úmidos de milho indicam que este alimento se mostra promissor quanto à substituição do grão de milho seco em rações para eqüinos.

- Não ocorreram efeitos negativos de ingestão e, ou palatabilidade no uso do concentrado com silagem de grãos úmidos de milho e também não foram observados distúrbios gastrointestinais.

- Os concentrados para potros em crescimento, em pastagens de capim Tifton 85 (Cynodon spp. L), podem ser formulados com substituição total do milho grão seco pela silagem de grãos úmidos de milho, sem prejuízo sobre o desempenho dos animais, tornando-se, assim, uma alternativa para a alimentação de eqüinos.

Os resultados do mesmo estudo indicam que a inclusão da silagem de grãos úmidos de milho melhorou a digestibilidade da matéria seca e da energia da dieta teste. Este fato, provavelmente, é devido aos processos fermentativos ocorridos no interior do silo, propiciando melhor disponibilidade do amido à ação das enzimas digestivas (SANTOS et al., 2002).

MEYER (1995), ressalta que a silagem de milho é pobre em proteína e desequilibrada em minerais e vitaminas, mas rica em energia com alto teor de 
gorduras $(8 \mathrm{~g} / \mathrm{kg})$. Por sua relação proteína bruta/energia ser de cerca de 4,5:1, é excepcionalmente apropriada para cavalos de equitação com baixa necessidade em energia. Esses animais podem ingerir cerca de $3 \mathrm{~kg}$ diários de silagem para cada $100 \mathrm{~kg}$ de peso vivo. Éguas de cria e potros devem ficar abaixo desse valor devido à sua maior necessidade de proteína. Suas dietas devem ser corrigidas com concentrado e sal mineralizado.

\subsection{Silagem de Sorgo}

O sorgo é uma forrageira que deve ser utilizada com cautela. Apesar de ser um bom substituto para o milho devido ao seu alto teor energético, apresenta algumas complicações de uso. Sua digestibilidade tende a ser menor que a do milho, pois suas sementes são menores, o que dificulta a trituração durante a mastigação. Ou seja, grande quantidade dos grãos não é mastigada, chegando inteira ao intestino, o que pode causar distúrbios intestinais.

Segundo HENRIQUES et al. (1997), a planta do sorgo possui, nas fases iniciais do seu desenvolvimento, o glicosídio durrina - em especial nas folhas e caule. Por hidrólise enzimática, essa substância libera ácido cianídrico, o que em certas condições pode provocar intoxicação nos animais. Para evitar possíveis intoxicações em eqüinos provocadas pela ingestão de doses elevadas de ácido cianídrico, deve-se esperar que o cereal cultivado atinja $50-70 \mathrm{~cm}$ de altura ou que haja seu florescimento (isso permite assegurar que o ácido presente já não é susceptível de provocar intoxicação). Ensilar também é uma maneira de evitar intoxicação, pois a fermentação inativa a durrina. Mesmo assim, deve-se tomar especial cuidado com o sorgo congelado, murcho, espezinhado ou atacado pela seca ou por parasitas.

\subsection{Silagem de gramíneas}

Devido ao seu maior teor de proteína, silagens de gramíneas ou trevos com matéria seca acima de $30 \%$ são muito apropriadas para éguas de cria e potros em crescimento. A quantidade diária é orientada segundo a matéria 
seca, sendo normalmente de 1 a $2 \mathrm{~kg}$ por $100 \mathrm{~kg}$ de peso vivo. Normalmente suplementa-se a dieta com grãos ou outras fontes de energia (MEYER, 1995).

É mais difícil se obter silagens de qualidade quando se utilizam gramíneas devido à sua baixa concentração de carboidratos. Geralmente $\mathrm{opH}$ não abaixa o suficiente, ou não na velocidade adequada, o que prejudica o produto final. Os capins mais utilizados na confecção de silagens são os capinselefantes (Pennisetum spp.), como o Napier, devido ao seu nível relativamente alto de açúcares e à sua alta produção por hectare (PEREIRA \& REIS, 1991).

\subsection{Silagem de Leguminosas}

As leguminosas forrageiras, devido à sua estrutura anatômica, baixo teor de açúcar e grande capacidade tamponante, são menos propícias a sofrer uma fermentação adequada e a fornecer um produto final de qualidade. Deste modo, a adição de aditivos pode ser uma vantagem para essa classe de plantas, como a alfafa forrageira (Medicago sativa) (RUIZ, 1992).

Sabe-se que a rápida redução do $\mathrm{pH}$ na silagem é essencial para se reduzir as alterações indesejáveis, como por exemplo as atividades das enzimas provenientes das plantas e a fermentação dos clostrídeos. Portanto, o uso de inoculantes à base de Lactobacillus spp. e Streptococcus spp. torna-se recomendável em silagens de leguminosas (MCDONALD, HENDERSON E HERON, 1991).

\subsection{Forragens Pré-Secadas}

Em se tratando de forrageiras com matéria seca inferior a $21 \%$, carboidratos solúveis inferiores a $2,2 \%$ na matéria verde e baixa relação entre carboidratos e poder tampão, os riscos de fermentações secundárias são maiores, tornando-se imprescindível o uso de recursos que, de alguma forma, modifiquem esta situação (MCDONALD, HENDERSON E HERON, 1991).

A remoção parcial de água da planta por meio de murchamento ou présecagem pode ser uma opção interessante, por proporcionar condições ideais 
RAINERI, C. e STIVARI, S.S. Utilização da silagem para alimentação de eqüinos. PUBVET, Londrina, V. 7, N. 24, Ed. 247, Art. 1636, Dezembro, 2013.

para o crescimento de bactérias láticas, e assim permitir que o excedente da forragem produzida possa ser armazenado (ANDRIGUETTO et al., 1983).

MCDONALD, HENDERSON E HERON (1991) constataram que a présecagem permite a ensilagem de plantas forrageiras com teores mais elevados de umidade, num processo relativamente simples onde fermentações indesejáveis são controladas através da diminuição da atividade de água ou elevação da pressão osmótica. Segundo WOOLFORD (1984), silagens com maior conteúdo de MS estabilizam em pH mais alto devido à menor atividade de bactérias do gênero Clostridium, que são sensíveis à pressão osmótica.

O processo consiste em cortar as plantas e deixá-las murchar no campo até que sua umidade atinja cerca $40-45 \%$, tomando-se o cuidado de revirá-la para que seque rápido e uniformemente. Então a forragem é recolhida e ensilada, daí a sensível redução nos riscos de perda da forragem conservada ensilada em relação ao feno, que deve permanecer muito mais tempo no campo até ser recolhido (PEREIRA \& REIS, 2001).

As forrageiras mais utilizadas para produção de silagem pré-secada são as gramíneas de clima temperado, como aveia, azevém, e cevada. Mais recentemente gramíneas tropicais como as espécies do gênero Cynodon "tiftons", "coastcross" - e até algumas braquiárias começaram a ser ensiladas. Dentre as leguminosas somente a alfafa é utilizada em quantidade expressiva (PEREIRA \& REIS, 2001).

Por ser produzida a partir de forrageiras tradicionalmente utilizadas para eqüinos, a silagem pré-secada constitui uma boa alternativa para propriedades que sofrem escassez de volumoso nas secas, ou para regiões nas quais o custo do feno é elevado demais. Atualmente existe grande variedade de máquinas para sua produção, como segadeiras condicionadoras, implementos que embalam grandes fardos, entre outros (PEREIRA \&REIS, 2001).

As segadeiras condicionadoras possuem roletes que esmagam as plantas cortadas, reduzindo pela metade o tempo de secagem das forrageiras, devido ao aumento da perda de água pelo caule (ROTZ E MUCK, 1994). Esse processo pode ser especialmente vantajoso para espécies de talos grossos e 
RAINERI, C. e STIVARI, S.S. Utilização da silagem para alimentação de eqüinos. PUBVET, Londrina, V. 7, N. 24, Ed. 247, Art. 1636, Dezembro, 2013.

leguminosas, pois, além de acelerar a secagem, reduz a perda de folhas. Essa perda ocorre principalmente quando as leguminosas são enfenadas, porque o tempo necessário para o caule perder água é excessivo para as folhas, que acabam caindo (PEREIRA \& REIS, 2001).

Porém, para forragens que foram submetidas a algum tipo de condicionamento mecânico as perdas decorrentes da ação da chuva sobre a forragem podem ser de maior intensidade, devido ao fato de que compostos solúveis de alto valor nutritivo são arrastados, podendo haver grandes perdas desses nutrientes (COLLINS, 1995).

$O$ recolhimento da forragem pode ser feito utilizando-se uma ensiladeira, desde que adaptado um "pente" apropriado. A forragem recolhida e picada deve ter tamanho de partícula entre 2 a $3 \mathrm{~cm}$ o que facilita sua distribuição, compactação no silo e posterior retirada, mesmo para níveis de matéria seca mais elevados (45\%) (PEREIRA \& REIS, 2001).

Também tem sido crescente no Brasil a ensilagem de forragem présecada em fardos redondos (400 a $600 \mathrm{~kg}$ ) revestidos com plástico especial. PEREIRA \& REIS (2001) citam como vantagens deste processo: 1) Permitir o uso de equipamentos empregados no processo de fenação para produção de silagem; 2) Possibilitar o transporte de pequenas quantidades de forragem conservada sem abertura de silos; 3) Não requerer estruturas de silos.

Os aspectos a serem considerados são: 1) Investimento elevado na aquisição de equipamentos e do plástico apropriado, sendo uma alternativa mais viável para empresas que comercializam volumosos; 2) 0 tempo de conservação da forragem é bem menor que dos silos convencionais.

\subsection{Outras Silagens}

$\mathrm{Na}$ Europa são feitas silagens de outros vegetais, como de bagaço de beterraba açucareira prensada e folhagem de cenoura. No Brasil, está sendo estudada a possibilidade da utilização de outros tubérculos, como a mandioca, para esse fim. Ainda não se testou a viabilidade desse alimento para eqüinos, 
mas já se obtiveram silagens de mais de $16 \%$ de proteína bruta e muito ricas em energia (MARCENAC, 1990).

\section{Conclusão}

O mundo do cavalo é bastante inflexível em se tratando de mudanças. Qualquer modificação no manejo ou tratamento dos animais é encarada com desconfiança por criadores, treinadores e proprietários.

Mudar a alimentação dos animais, mesmo que seja para se trocar um produto por outro de qualidade semelhante, porém de preço mais baixo, é sempre difícil.

Sob o ponto de vista nutricional, a possibilidade de se suplementar a dieta de cavalos com silagem é viável, especialmente no inverno. Para tal, a melhor opção seria a silagem de milho, seguindo-se sempre os cuidados básicos para produção de um bom ensilado, além de observar a quantidade fornecida aos animais, o balanceamento da alimentação e sua compatibilidade com a atividade desempenhada pelo animal.

Os pré-secados também consistem em boa alternativa, talvez a mais facilmente aceita pelo meio eqüestre por serem produzidos a partir de forragens muito consumidas por eqüinos, como alfafa, aveia, tiftons e coastcross. Neste caso deve-se dar atenção especial à picagem e compactação do material.

Os únicos obstáculos para a disseminação dessas técnicas são o preconceito dos criadores em adotar para seus cavalos um alimento tradicionalmente utilizado para bovinos e a atenção especial que se deve dispensar para o processo de ensilagem e a qualidade de sua matéria prima.

\section{Referências Bibliográficas}

ANDRIGUETTO et al., Nutrição Animal., São Paulo: Nobel, 1983, 425 p.

CASTRO et al., 1989. O Botulismo na indústria alimentar e seu impacto na sanidade animal e humana. [on line] Capturado em 17 de agosto de 2001. Disponível na URL: http://www.fmv.utl.pt/democ/sft/sem0008/G32.html 
$\mathrm{CHURCH}, \mathrm{D}$. C., Bases cientificas para la nutrición y alimentación de los animales domesticos., Zaragoza: Editorial Acribia, 1977, 492 p.

COLLINS, M. Hay preservation effects on yield and quality. In: MOORE, K.J.; KRAL, D.M.; VINEY, M.K. (eds). Post-harvest physiology and preservation of forages. Madison: American Society of Agronomy, 1995. p.67-89.

DANIEL, P.; HONIG, H.; WEISE, F.; ZIMMER, E. - Wirkung von Propionsaure bei der Grünfuttersilierung. IN: Microbiologia Zootécnica. RUIZ., R.L., 1992., Editora Roca, São Paulo, 314 p.

HENRIQUES et al., 1997, Intoxicação de cavalos pelo sorgo. [on line] Capturado em 14 de agosto de 2002. Disponível na web na URL: http://www.fmv.utl.pt/democ/sft/sem0001/G12.html

JOBIM,C. C., Produção e utilização de silagem de grãos de cereais., IN: II Simpósio de Forragicultura e Pastagens, Anais... Lavras - MG, 2001.

JONSSON, A. \& PAHLOW, G. Systematic classification and biochemical characterization of yeasts growing in a grass silage inoculated with Lactobacillus cultures. Animal Research Development, 20:7-22, 1984

KIENZLE, E. Small intestinal digestion of starch in the horse. Revue de Médicine Véterinaire, Toulouse, v.145, n.2, p.199-201, 1994.

LEWIS, L. D., Alimentação e cuidados do cavalo., São Paulo: Roca, 1985, 248 p.

MARCENAC, L.N., AUBLET, H., D'AUTHEVILLE, P., Enciclopédia do cavalo., São Paulo: Organização Andrei, 1990, 1463 p.

MCDONALD, P.; HENDERSON, A.R.; HERON, S.J.E. The biochemistry of the silage. Edinburg: J. Wiley and Sons, 1991. 226p.

MEYER, H., Alimentação de Cavalos., São Paulo: Editora Varela, 1995, 280p.

NRC - NATIONAL RESEARCH COUNCIL. Nutrient Requirements of Horses, Fifth Revised Edition, Washington: National Academy Press, 1989, $101 \mathrm{p}$.

PEREIRA, J. R. A. \& REIS, R. A., Produção e Utilização de Forragem Pré-Secada IN: II Simpósio de Forragicultura e Pastagens, Anais... Lavras - MG, 2001.

PILLINER, S. Nutrición y alimentación del caballo .España : Acribia, 1992. 207p.

ROTZ, C.A. Field curing of forages. In: MOORE, K.J.; KRAL, D.M.;VINEY, M.K. (eds). Postharvest physiology and preservation of forages. Madison: American Society of Agronomy, 1995. p.39-66.

ROTZ, C.A.; MUCK, R.E. Changes in forage quality during harvest and storage. In: FAHEY JUNIOR, G.C. (ed.). Forage quality, evaluation, and utilization. Madison: ASA/CSSSA/SSSA. p.828-868. 1994.

RUIZ., R.L., 1992., Microbiologia Zootécnica., Editora Roca, São Paulo, 314 p.

SANTOS et al., 2002., Evaluation of high moisture corn silage for growing horses diets: Nutritional value and performance., Revista Brasileira de Zootecnia., 31 (3): 1214-1222 Maio-Junho 2002.

SHAVER, R. D., Feed delivery and bunk management aspects of Laminitis in dairy herds fed total mixed rations. [on line] Capturado em 15 de agosto de 2002. Disponível na web na URL: http://www.wisc.edu/dysci/uwex/nutritn/pubs/ITALY00.pdf

UZAL, F.A., KELLY ,W.R. The effects of experimental intravenous inoculation of Clostridium perfringens type $D$ epsilon toxin on goat kids and on lambs. Journal of Comparative Pathology, v.116, p.63-71, 1997. 
WOLTER, R. Alimentación del caballo. Zaragoza: Acribia, 1977. 172 p.

WOOLFORD, M.K. The silage fermentation. New York: Marcel Dekker, 1984. 350 p. 